\title{
Analisis Pelayanan Badan Administrasi Akademik dan Kemahasiswaan terhadap Kepuasan Mahasiswa STIE Yadika Bangil
}

\author{
Ufi Rumefi \\ Akuntansi, STIE Yadika Bangil \\ e-mail: ufi.rumefi@yahoo.com
}

\begin{abstract}
This research was conducted to find out if BAAK services including The Facilities and Infrastructure Subsection (X1), Student Subsection (X2), Financial SubSection (X3) and Academic Subsection (X4) partially or simultaneously affect the satisfaction of the student $(Y)$, the purpose in this study is to know and explain the influence of sub-sections Facilities and Infrastructure (X1), Student Subsection (X2), Finance SubSection (X3) and Academic Subsection (X4) partially or simultaneously against student satisfaction (Y) sample in this study are students who have frequency of visitation rate at BAAK more than 12 times in one month. The results of the study obtained adjusted $R$ skuare of .815 this means that $81.5 \%$ of free variables affect bound variables, Variable X2 up to variable X4 affects variable $Y$ with sig value $<0.05$ while variable X1 does not affect variable $Y$ with sig value of 0.05 .
\end{abstract}

Keywords: Academic Service, Student Affairs, Satisfaction

\begin{abstract}
Abstrak
Penelitian ini dilakukan untuk mengetahui apakah pelayanan BAAK yang meliputi Sub bagian Sarana dan Prasarana (X1), Sub bagian Kemahasiwaan (X2), Sub Bagian Keuangan (X3) dan Sub bagian Akademik (X4) secara parsial maupun secara simultan berpengaruh terhadap kepuasaan mahaiswa (Y), Tujuan dalam penelitian ini adalah untuk mengetahui dan menjelaskan pengaruh Sub bagian Sarana dan Prasarana (X1), Sub bagian Kemahasiwaan (X2), Sub Bagian Keuangan (X3) dan Sub bagian Akademik (X4) secara parsial maupun secara simultan terhadap kepuasaan mahaiswa $(\mathrm{Y})$ sample dalam penelitian ini adalah mahasiswa yang mempunyai frekuensi tingkat kunjungan pada BAAK lebih dari 12 kali dalam satu bulan. hasil penelitian didapatkan adjusted $R$ square sebesar .815 hal ini berarti $81,5 \%$ variabel bebas mempengaruhi variabel terikat, Variabel X2 sampai dengan variabel X4
\end{abstract}


mempengaruhi variabel Y dengan nilai sig $<0,05$ sedangkan variabel X1 tidak mempengaruhi variabel $Y$ dengan nilai sig $>0,05$.

Kata Kunci: Pelayanan Akademik, Kemahasiswaan, Kepuasaan

\section{PENDAHULUAN}

Pada dasarnya, pengertian kepuasan atau ketidakpuasan pelanggan merupakan perbedaan antara harapan dan kinerja yang dirasakan, Philip Kotler mengatakan bahwa kepuasan adalah hasil yang dirasakan oleh konsumen yang mengalami kinerja, sebuah lembaga yang sesuaidengan harapannya. Jika suatu instansi pemerintah dan lembaga lainnya mampu menerapkan standar kualitas tersebut maka sudah dapat dikatakan bahwa Instansi pemerintah dan lembaga tersebut telah memberikan kualitas pelayanan yang baik. (Mahyaruddin, 2020)

BAAK (Badan Administrasi Akademik dan Kemahasiswaan) merupakan barisan terdepan dalam memberikan pelayanan pada sekolah tinggi. segala aktivitas pelayanan baik mahasiswa ataupun dosen dan bertumpu pada pelayanan BAAK begitu pentingnya peranan BAAK (Badan Administrasi Akademik dan Kemahasiswaan) dalam sekolah tinggi membuat BAAK harus menjaga dan memberikan pelayanan terbaik sehingga akan muncul pandangan yang terbaik bukan hanya untuk BAAK tapi juga untuk pihak sekolah tinggi tempat BAAK bernaung.

Penelitian ini penting di lakukan dengan harapan agar bisa menjadi koreksi bagi pihak BAAK STIE Yadika Bangil dalam hal Akademik maupun non akademik sehingga dapat di kerucutkan tujuan dari penelitian ini adalah untuk mengetahui dan menjelaskan pengaruh Sub bagian Sarana dan Prasarana (X1), Sub bagian Kemahasiwaan (X2), Sub Bagian Keuangan (X3) dan Sub bagian Akademik (X4) secara parsial maupun secara simultan terhadap kepuasaan mahaiswa (Y).

Hasil penelitian penelitian terdahulu yang berjudul Pengaruh Kualitas Pelayanan Administrasi Akademik Terhadap Kepuasan Mahasiswa Di Subbag Akademik, Kemahasiswaan, dan Alumni Fakultas Ekonomi Univesitas Negeri 
Surabaya menunjukkan bahwa nilai t-hitung kualitas pelayanan administrasi akademik (X) terhadap kepuasan mahasiswa (Y) adalah 6,771 dimana lebih besar dari ttabel sebesar 1,968. Maka dapat disimpulkan kualitas pelayanan administrasi akademik berpengaruh terhadap kepuasan mahasiswa di Subbag Akademik, Kemahasiswaan, dan Alumni Fakultas Ekonomi Universitas Negeri Surabaya. Selanjutnya kualitas pelayanan administrasi akademik (X) berpengaruh sebesar 12\% terhadap kepuasan mahasiswa (Y) dan sisanya dipengaruhi oleh variabel lain yang tidak diteliti dalam penelitian ini. (Amalina, 2018).

\section{METODE PENELITIAN}

Metode penelitian yang dipakai dalam penelitian ini adalah analisis regresi linear berganda dengan menggunkan alat bantu uji SPSS, Pengambilan sampel dalam penelitian ini menggunkan Purposive sampling dengan kriteria mashasiswa yang menjadi responden adalah mahasiswa yang mempunyai tingkat kunjungan ke BAAK lebih dari 12 kali dalam satu bulan karena responden tersebut dianggap paling sering memperoleh pelayanan dari BAAK, dari total 312 mahasiswa sebanyak 64 mahasiswa melakukan kunjungan ke BAAK lebih dari 12 kali dalam satu bulan. Alat uji dalam penelitian ini menggunakan SPSS.

Berikut merupakan kerangka pikir dari penelitian yang dilakukan.

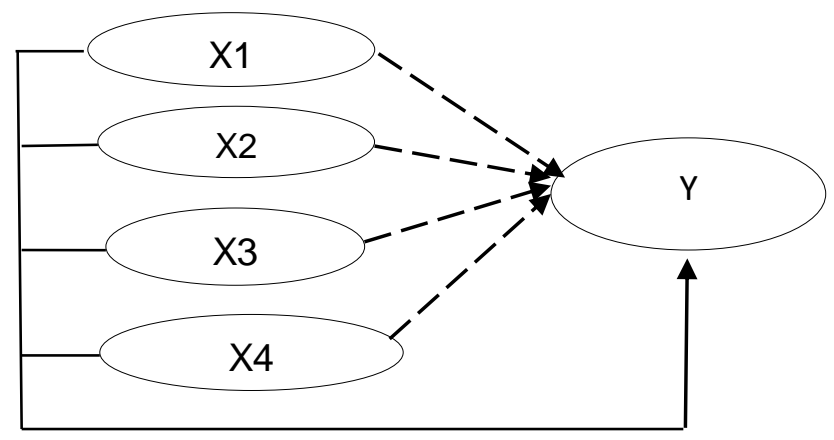

Gambar 1. Kearangka Berpikir 
Berikut merupakan Definisi Operasional Variabel penelitian:

Tabel 1. Definisi Operasional Variabel

\begin{tabular}{|c|c|c|}
\hline $\begin{array}{l}\text { Variabel } \\
\text { Penelitian }\end{array}$ & Definisis Operasional & Indikator Penelitian \\
\hline $\begin{array}{l}\text { Sub Bagian Sarana } \\
\text { Dan Prasarana (X1) }\end{array}$ & $\begin{array}{l}\text { Sub Bagian Sarana adalah peralatan } \\
\text { dan perlengkapan yang secara } \\
\text { langsung dan tidak langsung } \\
\text { dipergunakan untuk menunjang } \\
\text { proses pendidikan, khususnya } \\
\text { proses belajar mengajar, seperti } \\
\text { gedung, ruang kelas, meja kursi, } \\
\text { serta alat-alat dan media pengajaran. } \\
\text { (Habib, 2020) }\end{array}$ & $\begin{array}{l}\text { 1. Kecakapan dalam menjaga } \\
\text { Kebersihan Lingkungan, Gedung, } \\
\text { dan menjaga Fungsi gedung serta } \\
\text { perangkatnya. } \\
\text { 2. Kepedulian dalam keamanan } \\
\text { Aksesibilitas data dan informasi. } \\
\text { 3. Kecepatan dalam menanggapi } \\
\text { keluhan berkaitan dengan sarana } \\
\text { dan prasarana. }\end{array}$ \\
\hline $\begin{array}{l}\text { Sub Bagian } \\
\text { Kemahasiswaan } \\
\text { (X2) }\end{array}$ & $\begin{array}{l}\text { Sub Bagian kemahasiswaan } \\
\text { memiliki tugas memberikan } \\
\text { pelayanan kepada mahasiswa untuk } \\
\text { menwujudkan atribut soft skill yang } \\
\text { sesuai dengan nilai budaya } \\
\text { universitas. (Sarwani, 2020) }\end{array}$ & $\begin{array}{l}\text { 1. Kemudahan di temui pada saat di } \\
\text { butukan. } \\
\text { 2. Kecakapan dalam menyelesaikan } \\
\text { keluhan } \\
\text { kemahsiswaan administrasi } \\
\text { 3. Keramahan dan kemampuan } \\
\text { berkomunikasi dengan mahasiswa }\end{array}$ \\
\hline $\begin{array}{l}\text { Sub Bagian } \\
\text { Keuangan (X3) }\end{array}$ & $\begin{array}{l}\text { Sub bagian ini mempunyai tugas } \\
\text { menyelenggarakan kegiatan dan } \\
\text { dukungan administrasi dalam } \\
\text { bidang penganggaran, } \\
\text { perbendaharaan, akuntansi dan } \\
\text { pelaporan. (Putri, 2017) }\end{array}$ & $\begin{array}{l}\text { 1. Kecakapan dalam penguasaan } \\
\text { informasi terkait dengan informasi } \\
\text { keuangan mahasiswa. } \\
\text { 2. Kemudahan di temui saat di } \\
\text { butuhkan } \\
\text { 3. Kecepatan dan Keramaan dalam } \\
\text { berkomunikasi dengan mahasiswa } \\
\text { tentang hal-hal yang berkaitan } \\
\text { dengan keuangan mahasiswa }\end{array}$ \\
\hline $\begin{array}{l}\text { Sub Bagian } \\
\text { Akademik (X4) }\end{array}$ & $\begin{array}{l}\text { Sub bagian Akademik yaitu } \\
\text { serangkaian aktivitas yang bersifat } \\
\text { tidak kasat mata dan kasat mata dari } \\
\text { pihak institusi kepada civitas } \\
\text { akademika. (Thadi, 2020) }\end{array}$ & $\begin{array}{l}\text { 1. Kecepatan dalam pelayanan Surat } \\
\text { menyurat. } \\
\text { 2. Kecakapan dalam menyelesaikan } \\
\text { keluhan administrasi akademik. } \\
\text { 3. Keramaan saat di temui. }\end{array}$ \\
\hline $\begin{array}{l}\text { Kepuasaan } \\
\text { Mahasiswa (Y) }\end{array}$ & $\begin{array}{l}\text { Kepuasan merupakan fungsi dari } \\
\text { kesan kinerja (Majid, 2020) }\end{array}$ & $\begin{array}{l}\text { 1. Terpenuhi kebutuhan akan } \\
\text { pelayanan yang di harapkan. } \\
\text { 2. Keseesuaian antara Penjelasan } \\
\text { dengan harapan. } \\
\text { 3. Penyampaian informasi yang cepat } \\
\text { saat di butuhkan. }\end{array}$ \\
\hline
\end{tabular}

Sumber: data di olah 2020

Ufi Rumefi - Analisis Pelayanan Badan Administrasi Akademik dan Kemahasiswaan terhadap Kepuasan Mahasiswa STIE Yadika Bangil 


\section{HASIL PENELITIAN}

1. Hasil Analisis Regresi Linear Berganda

Tabel 2. Analisis Persamaan Regresi Linier Berganda

\begin{tabular}{|c|c|c|c|c|c|}
\hline \multicolumn{6}{|c|}{ Coefficients $^{\mathrm{a}}$} \\
\hline \multirow{2}{*}{\multicolumn{2}{|c|}{ Model }} & \multicolumn{2}{|c|}{ Unstandardized Coefficients } & \multirow{2}{*}{\multicolumn{2}{|c|}{$\begin{array}{c}\begin{array}{c}\text { Standardized } \\
\text { Coefficients }\end{array} \\
\text { Beta }\end{array}$}} \\
\hline & & B & Std. Error & & \\
\hline 1 & (Constant) & .303 & .230 & & \\
\hline & $\mathrm{X} 1$ & .071 & .138 & & .075 \\
\hline & $\mathrm{X} 2$ & .296 & .112 & & 297 \\
\hline & X3 & .243 & .103 & & 260 \\
\hline & $\mathrm{X} 4$ & .311 & .139 & & .338 \\
\hline
\end{tabular}

a. Dependent Variable: $Y$

Sumber :Data Output SPSS 16 diolah 2020

Dari hasil analisis regresi linier berganda diperoleh persamaan sebagai berikut :

$$
\mathrm{Y}=0,303+0,071 \mathrm{X} 1+0,296 \times 2+0,243 \times 3+0,311 \times 4+\mathrm{e}
$$

Hasil penjelasan dari persamaan regresi linier berganda adalah sebagai berikut:

a. Jika Variabel (X1), (X2), (X3), dan (X4) sama dengan 0 maka besaran variabel Y adalah 0,303

b. Jika X1 (Sub bagian Sarana dan Prasaran) dianggap 1 maka akan di peroleh persamaan $\mathrm{Y}=0,303+0,071$. Artinya jika $\mathrm{X} 1$ naik 1 tingkat maka Ynaik sebesar 0,071.

c. Jika X2 (Sub bagian Kemahsiswaan) dianggap 1 maka akan diperoleh persamaan $Y=0,303+0,296$.Artinya jika X2 naik 1 tingkat maka Ynaik sebesar 0,296

d. Jika X3 (Sub bagian Keuangan) dianggap 1 maka akan diperoleh persamaan $Y=0,303+$ 0,243.Artinya jika X3 naik 1 tingkat maka Ynaik sebesar 0,243 
e. Jika X4 (Sub bagian Akademik) dianggap 1 maka akan diperoleh persamaan $Y=0.303+0,311$.Artinya jika $\mathrm{X} 4$ naik 1 tingkat maka Ynaik sebesar 0,311

2. Analisis Koefisien Determinasi

Tabel 3. Koefisien Determinasi

\begin{tabular}{|l|r|r|r|r|r|}
\hline & & & \multicolumn{1}{c|}{ Model Summary } \\
Model & $\mathrm{R}$ & R Square & $\begin{array}{c}\text { Adusted R } \\
\text { Square }\end{array}$ & $\begin{array}{c}\text { Std. Error of the } \\
\text { Estimate }\end{array}$ & $\begin{array}{c}\text { Durbin- } \\
\text { Watson }\end{array}$ \\
\hline 1 & $.909 \mathrm{a}$ & .827 & .815 & .24707 & 2.342 \\
\hline
\end{tabular}

a. Predictors: (Constant), X4, X3, X2, X1

b. Dependent Variable: Y

Sumber :Data Output SPSS 16 diolah 2020

Hasil perhitungan regresi dapat diketahui bahwa korelasi atau hubungan antara variabel Kepuasaan Mahasiswa dengan seluruh variabel bebas yaitu Sub bagian Sarana dan Prasarana (X1), Sub bagian Kemahasiwaan (X2), Sub Bagian Keuangan (X3) dan Sub bagian Akademik (X4) adalah 0,827 > 0,05. Sedangkan koefisen regresi atau pengaruh pada determinasi (adjusted $R^{2}$ ) di peroleh sebesar 0,815.Hal ini berarti 81,5\% kepuasaan Mahasiswa dipengaruhi oleh variabel bebas yaitu Sub bagian Sarana dan Prasarana (X1), Sub bagian Kemahasiwaan (X2), Sub Bagian Keuangan (X3) dan Sub bagian Akademik (X4) sedangkan sisanya sebesar $18,5 \%$ diterangkan variabel lain seperti rasa nyaman dalam kegitan Belajar.

\section{Pengujian Hipotesis}

a. Hasil Pengujian Hipotesis I (UjiF / Simultan)

Tabel 4. Hasil Uji F

\begin{tabular}{|c|c|c|c|c|c|c|}
\hline \multicolumn{7}{|c|}{ ANOVA $^{\mathrm{b}}$} \\
\hline \multicolumn{2}{|c|}{ Model } & Sum of Squares & $\mathrm{df}$ & Mean Square & $\mathrm{F}$ & Sig. \\
\hline 1 & $\begin{array}{l}\text { Regressio } \\
\mathrm{n}\end{array}$ & 17.180 & 4 & 4.295 & 70.359 & $.000^{\mathrm{a}}$ \\
\hline & Residual & 3.601 & 59 & .061 & & \\
\hline & Total & 20.781 & 63 & & & \\
\hline
\end{tabular}


ANOVA $^{\mathrm{b}}$

\begin{tabular}{|c|c|c|c|c|c|c|}
\hline \multicolumn{2}{|c|}{ Model } & Sum of Squares & df & Mean Square & $\mathrm{F}$ & Sig. \\
\hline 1 & $\begin{array}{l}\text { Regressio } \\
n\end{array}$ & 17.180 & 4 & 4.295 & 70.359 & $.000^{\mathrm{a}}$ \\
\hline & Residual & 3.601 & 59 & .061 & & \\
\hline & Total & 20.781 & 63 & & & \\
\hline
\end{tabular}

a. Predictors: (Constant), X4, X3, X2, X1)

b. Dependent Variable: Y

Sumber :Data Output SPSS 16 diolah 2020

Berdasarkan perhitungan diperoleh nilai F hitung sebesar 70,359.Sedangkan $\mathrm{F}$ tabel (df1 $=4 \mathrm{dan}$ df2 $=59$ ) sebesar 2,53 dengan level of significant( ) sebesar 0,05 dan sig Fsebesar 0,000. Karena F hitung > F tabel yaitu 70,359>2,53 dan sig $F<$ level of signify cant (a) yaitu 0,000 < 0,05 maka Ho ditolak Ha diterima. Ha diterima, maka dapat disimpulkan bahwa variabel independen yang meliputi sub bagian sarana adan prasarana (X1), Sub bagian Kemahasiswaan (X2), Sub bagian Keuangan (X3) dan Sub bagian akademik (X4) secara simultan atau bersama-sama mempengaruhi variabel Kepuasaan Mahasiswa (Y) secara signifikan

b. Hipotesis II (UjiT/Parsial)

Tabel 5. Hasil Pengujian Uji t

Coefficients $^{\mathbf{a}}$

\begin{tabular}{|c|c|c|c|c|c|}
\hline \multirow[b]{2}{*}{ Model } & \multicolumn{2}{|c|}{$\begin{array}{l}\text { Unstandardized } \\
\text { Coefficients }\end{array}$} & \multirow{2}{*}{$\begin{array}{c}\begin{array}{c}\text { Standardized } \\
\text { Coefficients }\end{array} \\
\text { Beta }\end{array}$} & \multirow[b]{2}{*}{$\mathrm{t}$} & \multirow[b]{2}{*}{ Sig. } \\
\hline & B & Std. Error & & & \\
\hline 1 (Constant) & .303 & .230 & & 1.320 & .192 \\
\hline $\mathrm{X} 1$ & .071 & .138 & .075 & .515 & .609 \\
\hline $\mathrm{X} 2$ & .296 & .112 & .297 & 2.628 & .011 \\
\hline X3 & .243 & .103 & .260 & 2.357 & .022 \\
\hline $\mathrm{X} 4$ & .311 & .139 & .338 & 2.246 & .028 \\
\hline
\end{tabular}

a. Dependent Variable: $Y$

Sumber :Data OutputSPSS 16 diolah 2020 
Berdasarkan perhitungan diperoleh nilai t tabel sebesar 2,00030 ( $\mathrm{df}$ residual $=64$ ) $\mathrm{n}-\mathrm{k} / 64-4=60$. Dengan level of significant ( $a$ ) sebesar 0,05. Dan diperoleh hasil sebagai berikut: Sub bagian Kemahasiwaan (X2), Sub Bagian Keuangan (X3) dan Sub bagian Akademik (X4) mempengaruhi variable kepuasaan mahaiswa (Y) karena di dapat nilai sig untuk masing-masing variable tersebut < dari 0,05 jika tulis secara berurutan sebesar 0,11 untuk variable X2, 0,22 untuk variabel X3 dan 0,28 untuk variabel X4, sedangkan variabel XI tidak mempengaruhi variabel Kepuasaan mahaiswa dengan nilai sig pada table $t$ sebesar 0,609>0,05 hal ini dapat di uraikan bahwah untuk sub bagian sarana dan prasaranan tidak mempengaruhi kepuasaan mahasiswa dalam pelaynan BAAK di karenakan tanggung jawab sub bagian sarana dan prasaran bukan sepenuhnya pada pihak BAAK.

\section{KESIMPULAN}

Kesimpulan dari hasil penelitian di atas adalah: variabel independen yang meliputi sub bagian sarana adan prasarana (X1), Sub bagian Kemahasiswaan (X2), Sub bagian Keuangan (X3) dan Sub bagian akademik (X4) secara parsial hanya variabel X1 yang tidak berpengaruh terhadap variabel $Y$ dengan nilai sig $>0,005$ yaitu sebesar 0,609 , sisanya variabel X2, X3 dan X4 berpengaruh tehadap variabel $\mathrm{Y}$ dengan nilai sig berturut-turut $0,11,0,22,0,28$.

Variabel independen yang meliputi sub bagian sarana adan prasarana (X1), Sub bagian Kemahasiswaan (X2), Sub bagian Keuangan (X3) dan Sub bagian akademik (X4) secara simultan atau bersama-sama mempengaruhi variabel Kepuasaan Mahasiswa $(\mathrm{Y})$ secara signifikan, dengan nilai adjusted $R$ square sebesar 0.815 atau $81,5 \%$ variabel bebas mempengaruhi variabel terikat.

\section{DAFTAR PUSTAKA}

Amalina Dzakiratullah, N. U. (2018). Pengaruh kualitas pelayanan administrasi akademik terhadap kepuasan mahasiswa di subbag akademik, 
kemahasiswaan, dan alumni fakultas ekonomi univesitas negeri surabaya. Inspirasi Manajemen Pendidikan. , 6(3).

Habib, M. S. (2020). Manajemen sarana dan prasarana dalam upaya meningkatkan mutu pembelajaran (studi komparatif pada madrasah aliyah negeri 1 mukomuko dengan madrasah aliyah miftahul ulum mukomuko).

Mahyaruddin, A. (2020). Analisis Kepuasan Mahasiswa Fakultas Ilmu Sosial Dan Ilmu Pemerintahan (FISIP) Terhadap Pelayanan Biro Bagian Administrasi Akademik Dan Kemahasiswaan UIN Ar-Raniry. Doctoral dissertation, UIN ARRANIRY.

Mahyaruddin, A. (2020). Analisis Kepuasan Mahasiswa Fakultas Ilmu Sosial Dan Ilmu Pemerintahan (FISIP) Terhadap Pelayanan Biro Bagian Administrasi Akademik Dan Kemahasiswaan UIN Ar-Raniry. Doctoral dissertation, UIN ARRANIRY.

Nusron A. 2019. Konsep dan Pembuatan Kuisioner Pelayanan BAAK. Diakses pada tanggal 08 Januari 2019

Putri, A. F. (2017). Pembuatan Portfolio Layanan TI Bidang Akademik, Kemahasiswaan, Keuangan, dan Sarana Prasarana Berdasarkan Service Strategy ITIL V3.

Sarwani, M. (2020). Rancang Bangun Aplikasi Manajemen Beasiswa Menggunakan Metode SAW pada Bagian Kemahasiswaan Universitas Dinamika.

Thadi, R. (2020). udit Komunikasi Organisasi Layanan Akademik di IAIN Bengkulu. Jurnal Penelitian Komunikasi , 23(1). 